\title{
Enhancement of Cognitive Functioning and Self-Regulation of Learning in Adolescents
}

\author{
María Luisa Sanz de Acedo Lizarraga and $\mathrm{M}^{a}$ Dolores Iriarte Iriarte \\ Public University of Navarra
}

This study assessed the effects of the adnintistration of a package of activities, known as Portfolio, on adolescents" cognitive functioning and self-regulation of learning. The study was carried out with a group of 109 students (mean age 15 years old) from the first level of Vocational Training. The students had learning difficulties, were unmotivated to study, and had behavior problems. A quasi-experimental pretest-posttest design was employed. The intervention involved group sessions in which certain. specially selected tasks from the psychopedagogic Instrumental Enrichment Program, the Philosophy for Children Progtam, and Project Intelligence were carried out. The intervention tasks were distributed wer the entire school year. Statistically significant differences were obscrved between the experimental and the control groups on measures of general intelligence, cognitive flexibility, and metacognitive strategies (all $p<.01$ ). Statistically significant gains were obscrved for the experimental group on measures of decision making, problem solving, and self-regulation of learning (all $p<.01$ ).

Key words: intelligence, cognitive flexibility, self-regulation. leaming program

El trabajo evaluó los electos de la aplicación de un paquete de actividades, conocido como Portafolio, en el funcionamiento cognitivo y en la autorregulación del aprendizaje de adolescentes. El estudio se llevó a cabo con una muestra de 109 alumnos del primer nivel de Formación Profesional que presentaban dificultades de aprendizaje, desmotivación hacia el estudio y problemas de conducta (edad media 15 años). Se utilizó un diseño cuasi-experimental, con mediciones pretest y postest. La intervención consistió en la ejecución de algunas tareas, seleccionadas ad hoc, de los programas psicopedagógicos Enriquecimiento Instrumental, Filosofía para Niños y Proyecto Inteligencia, a lo largo de un curso escolar en sesiones de grupo. Se observaron diferencias estadísticamente significativas entre el grupo experimental y el grupo control en las medidas de inteligencia general, flexibilidad cognitiva y estrategias metacognitjvas $(p<.01$ en todos los casos). Se observaron ganancias estadisticamente significativas en el grupo experimental en las medidas de toma de decisiones, solución de problemas y autorregulación del aprendizaje ( $p<.01$ en todos los casos).

Palabras clave: inteligencia, flexibilidad cognitiva, autorregulación, programa aprendizaje

Correspondence concerning this article should be addressed to; María Luisa Sanz de Acedo Lizarraga, Departamento de Psicología y Pedagogía. Campus de Arrosadia s/n. Universidad Pública de Navarra. 31006 Pamplona (Spain). Fax: 948-169169. E-mail: mlsa@unavarra.es 
There are essentially two approaches to in the scientific study of human intellectual competence. One approach focuses on theories that attempt to explain the nature of ontological quality of cognitive abilities (Gatdner: 1999; Greenspan \& Driscoll, 1997; Stemberg, 1985. 1986). The second approach, while not neglecting theoretical aspects, stresses the possibility of improving reflexive intclligence (Feuerstein, Rand, Hoffman, \& Miller, 1980; Perkins, 1995; Whimbey, 1975); critical thinking skills (Halpem, 1998; Klauer. 1998; Lipman, 1974; Swartz \& Parks, 1994); and metacognitive processes related to the planning an individual carries out betore initiating an activity, adjustments made during the activity, and re-examination after completing the activity (Bockaerts, 1997; García \& Pintrich, 1994; Hacker, Dunlosky, \& Griesser, 1998: Pressley, 1995; Schunk \& Zimmerman, 1994). Thesc authors, among many others, state that the processes involved in intelligent behavior can be positively modilied (De Bono, 1983; Perkins, Goodrich, Tishman, \& Mirman-Owen, 1994; Segal, Chipman, \& Glaser, 1985).

Practically all researchers involved in tcaching people how to think stress the role played by the teacher or medjator and by the educational and social environment in achicving significant changes in students' intellectual performance (Feuerstein, Klein, \& Tannenbaum, 199 I; Feuerstein et al., 1980; Gardner, 1993). Vygotsky (1978), in his construct of the proximal zone of development, stated that there is a considerable difterence between the performance level that an individual can attain by him- or herself and the one he or she can achieve with appropriate aid from an expert companion or an adult. According to this view, few individuals achieve optimal competence levels just through direct interaction with environmental stimuli. Enriching experiences provided by others are believed to help the individual realize his or her cognitive potential. Feuerstein et al. (1980) even declared that a lack of mediated learning experiences is a primary contributing fuctor to the occurrence of mental retardation or deficient functioning.

A relevant issue is how can significant changes in cognitive functioning be achieved? According to the literature and educational practice, the answer is to be found, mainly, in psychopedagogical programs and in the type of infusion methodology employed.

\section{Psychopedagogical Programs}

Many psychopedagogical programs have been designed to facilitate the development of thinking skills. These programs are adapted to various grade levels and to students" common cognitive requirements (Nickerson, Perkins, \& Sinith, 1985; Nisbet, 1993). The following programs are the most well known and widely used in Spain: (a) The Instrumental Enrichment Program (Feuerstein et al., 1980), (b) The Philosophy for Children Program (Lipman, 1974, 1976; Lipman, Sharp, \& Oscanyan, 1980), and (c) Project Intelligence, also known as ODYSSEY (Herrnstein,
Nickerson. Sanchez, \& Swets, 1986). Although the aim of each program is to stimulate thinking operations in general, they differ with respect to specific goals, the methodological strategies employed, and the didactic materials offered.

The Instrmmental Entichment Program. This progtam was designed in accordance with the assumptions of the structural cognitive modifiability theory by Feuerstein ot al. ([980). Among other goals, its aim is to enhance mental functioning and to develop self-regulatory behaviors. It is made up of 14 working instruments, of universill content. that can be administered for at least two school conrses to children over 10 yeats old. Each instrument drills the students in a certain function and cognitive operation and prepares them to understand other more complex operations. This program scoms mole efficient in some populations than in others. Significant improvement was observed when it was used with students whose incellectual functioning was low (Teucrstein et al., 1980; Rand, Tannenbaum, \& Feuerstein, 1979; Sanz de Acedo, 1989). This improvement persisted up to 2 years following instruction (Feuerstein ef al., 1981). However, when administered to ordinary learners, reports of success have been mixed. Changes in $1 Q$ and academic performance have been observed by Sanz de Acedo (1989, 1994) but not by Blagg (1991).

The Philosophy for Children Program. This program, by lipman $(1974,1976)$ and Lipman et al. (1980), was designed mainly to develop inductive thinking skills and metacognition. The program materials are in the form of novels that present pluilosophical and thought-related topics, such as the laws of logic, values, the usefultess of rules and reasoning. Typically, the novels are real and analyzed by students in groups, from kindergatten to high school. The Educalional Testing Service conducted extensive evaluations of this program, which showed positive results in reasoning, ideational fluency, and curiosity; however, effect sizes were not provided, so it is difficult 10 assess the magnitude of change (Psychological Corporation, 1978). Other studies carried out on this program also showed significant gains in learning transforence (lorio, Wcinstein, \& Martin, 1984; Shipman. 1983) and in reading comprehension, which was maintained 30 months after the intervention (see Lipmar et al., 1980).

Project Intelligence. This program, by Herrnstein et al. (1986), was designed to teach adolescents appropriate strategies to enable them to successfully perform tasks involving reasoning skills, problem-solving, decision-making, and creative thinking. The project has six instructional units that can be employed during the school year. Each unit has specific thinking goals. In the first formal evaluation carried out by Hernstein et al. with sudents from 24 classes, general aptitude gains were observed (effect sizes of $d=43, p<$ .001 , on the Otis-1.cnnon School Ability Test 10 tis \& Lennon, 19771: $d=.11, p<.02$, on the Cattell Culture Fair Test [Cattell \& Cattell, 1961]; and $d=.35, p<.001$, on the Test of General Ability [Manue], 1962]). Although the 
persistence of the elfects was not assessed, these results suggest that, at least in the short term, the intervention enhanced students' intelligent behavior.

The scientific success and drawbacks of these three programs have been analyzed by Chipman, Siegel, and Glaser (1985), Frisby and Braden (1992), Resnick (1987) and Tomic and Kingma (1996), among others. Program implementation appcars to produce some improvement in the processes of inductive and deductive reasoning, as well as in decisionmaking and problem-solving, although their effectiveness has been somewhat modest (Perkins \& Grotzer, 1997).

Based upon the foregoing reflections, the following six practices supporting successful outcomes of the psychopedagogical programs are offered for consideration, highlighting the most relevant aspects:

Emphasis is placed on self-regulation skills of learning, persuading students to plan, regulate, and evaluate their activities (Resing, 1997; Scardamalia \& Bereiter, 1985; Whimbey \& Lochlead, 1982)

Teachers actively mediate in task structure, the type of questions, and feedback.

Training requires a long-term commitment so that the changes achieved will be consolidated, maintained, and generalized (Howe. 1997: Tomic, Kingma, \& Tenvergert, 1993).

Transfer of program material matches students' needs, both in content and developmental stage, so that the learning can be optimal for each student (Klauer, 1989).

Instruclion supports the development of learning strategies that have been shown to lead to significant gains in comprehension.

The program fosters students' positive attitudes or dispositions toward the learning environment and their schooling activities, so they welcome the notion of performing cognitively (Ennis, 1986; Perkins, Jay, \& Tishman, 1993).

\section{Infusion Methodology}

Infusion methodology is the second solution to the issue of how cognitive lunctioning can be changed. This intervention style consists of teaching thinking strategies along with regular subject-matters, directly, explicitly, and simultancously (Swartz \& Perkins, 1989). This methodology is based on the concept that academic study offers many opportunities for reflection and for practicing various kinds of mental operations. Thus, the use of regular curricular material is the ideal, natural way of practicing and achieving the program goals. Few efforts have been reported aboul the conjoint study of skills and contents. This deficiency may be partly due to the fact that this methodology is recent in its development and partly due to the nature of the teaching-learning style, which generates several difficultto-control variables. Nevertheless, the infusion methodology is acknowledged as a promising strategy in education
(Gaskins \& Elliot, 1991; Schraer \& Stolze, 1987; Swartz, 1987, 1991; Swartz \& Parks, 1994; Tishman, Perkins, \& Jay, 1995). Compared to traditional teaching, infusion offers the advantage of increasing the probability of transferring to the student those processes, stratcgies, and the information acquired in order to succeed in academic activities (Simpson, Hynd, Nist, \& Burrel, 1997).

\section{Intervention Strategies}

The two research trends described as psychopedagogical programs and infusion methodology have been shown to be ellective even though they present certain practical problems. With regard to the psychopedagogical programs, among other aspects, the teachers frequently forget to focus specificaliy on the transference of selected skills to other learning situations. This circumstance is often ignored in the programs themselves. In most centers, teachers and administrators are unwilling to spend class time on the programs, and program implementation requires teachers who are trained in thinking processes. It is also difficult to maintain students' motivation throughout the intervention, although this problem also may be due to lack of teacher training. Similarly, infusion methodology also requires a lot of time and trained teachers to insure the positive integration of both teaching how to think and teaching subject matter. Without adequately trained teachers, researchers are in doubt about which is the better strategy to develop intellectual processes and structures.

Sevelal initiatives have been undertaken. One initiative involves the implementation of hybrid interventions that focus on the development of curriculum objectives, integrating teaching thinking skills with essential academic content in a direct and structured way. An example is the Practical Intelligence for School (PIFS) program (Stemberg \& Wagner, 1986), which offers a series of activities aimed at teaching useful cognitive skills and managing school tasks (Williams et al., 1996). According to Calderhead (1996), another initiative applies infusion mothodology during the primary elementary school years and the psychopedagogical programs are implemented at the secondary school level. The selection of the infusion approach relics on the practice at the primary school level, where the same teacher is responsible for instruction in nearly all the subject matters, fostering the integration of content with cognitive skills. On the other hand, in secondary schools, each teacher is responsible for a single subject area so that the students tend to reccive instruction from several teachers delivering curricula independently.

In the current research effort, we chose to examine the effects of the psychopedagogical programs, because the intervention was carried oul with students entolled in secondary education settings (Calderhead, 1996). However, we did not use any one of the three previously cited 
programs independently, but we chose to employ the Portfolio program that consists of activities extracted from all three programs: Instrumental Enrichment, Philosophy for Children, and Project Intelligence programs.

A number of issucs were taken into account in our decision to design this new package of tasks and to investigate its efficacy:

A record of over 15 years experience with each of the three programs lent weight to our observation that the programs appeared to promote strong intrinsic motivation at the beginning of the intervention; but as students mature, they tire and become bored, negatively affecting their attitudes toward the programs.

The Education Reformation (LOGSE, 1990) movement, and, in particular, our Iocal cducation policies, advises Secondary Education teachers to use materials from the three programs that make up the Portfolio in an optional course called "teaching to think."

The teachers from the center assigned to the experimental group asked us to train their students in specific cognitive processes that could be practiced and would complement each area if materials from all three programs were employed.

Although still inconclusive, interest in the underlying theoretical framework supporting portfolio centered the importance of mediated learning experiences, self-regulation of learning at both individual (Feuerstein et al, 1980) and group levels (Lipman, 1974, 1976), and the use of various instruction styles and educational material.

We wished to test the effectiveness of this package of activities, as we had been using it regularly for 3 years with Secondary Education students.

The purpose of this study was to assess the effects of the Portfolio program particularly with respect to the enhancement of cognitive functioning and self-regulation of learning in Secondary Education students.

\section{Method}

\section{Participants}

The population for this study was made up of students enrolled in 11 First-Level Vocational Training Centers in Pamplona during the academic year 1996-97. From these centers, two were randomly selected. In turn, one center was randomly assigned to the experimental group and the other to the control group. A total of 109 (27 boys and 82 girls) participated in the study; 50 in the experimental group ( 12 boys and 38 girls) and 59 in the control group (15 boys and 44 girls). The mean age was 15 years old (range 14-16 years). According to the teachers, although some students performed well at school, most of them were identified with behavior problems, learning difficulties, unskilled with respect to self-regulation of learning, and had little motivation to study.

\section{Instruments}

Both standardized and nonstandardized cvaluation instruments were employed. The latter were developed by the authors 10 gather additional information from the experimental group at the beginning and at the end of the intervention.

Standardized tests. Three standardized tests were employed: (a) The Culture Fair Intelligence Test, Scale 3 (Cattell. 1973); (b) "Test de Flexibilidad Cognitiva, Cambios" (Cognitive Flexibility Test. Changes; Seisdedos, 1994); and (c) "Escalas de Estrategia de Aprendizaje, Subescala IV" (The Learning Strategies Scales, Subscale IV: Roman \& Gallego, 1994).

Culure Fair Intelligence Test. Scale 3. This test measures the "g" Factor. The lasks require participants to use processes of comparison, classification, analysis, synthesis, decisionmaking, and problem-solving. The scale has been administered to students in other studies participating in the Instrument Enrichment and Project Intelligence programs. In our sample of 109 respondents. the reliability index of the test was .80 (split-half method, Spearman-Brown formula).

"Test de Flexibilidal Cognitiva, Cambios." This test assesses the individual's capacity to shift cognitively when faced with a changing situation that requires him or her to analyze, in a holistic way, whether the various changes requested in the item do take place. There are three kinds of possible changes: number of sides, size, and complexity of the inner pattern of the polygon. The test correlates with nomverbal intelligence and with reasoning tests. The reliability index of the test scores for the sample was .83 (split-half method, SpearmanBrown formula).

"Escalas de Estrategias de Aprendizaje, Subescala IV." This scale measures metacognitive strategies that facilitate mental information-processing. We obtained a reliability index of 73 for the sample (split-half mothod, SpcarmanBrown formula).

Nonstandardized tests. Three researcher-developed nonstandardized measures were employed: (a) The DecisionMaking Test, (b) The Problem-Solving Test, and (c) The Self-Regulation of Learning Test.

The Decision-Making Test (DM). This test provides information about how an individual takes the most important aspects into account in the decision process: (a) elaboration of alternatives, (b) analysis of pros and cons, (c) choice of the most appropriate altemative, and (d) consideration of the possible consequences of the decision. The instrument is made up of 10 statements requiring students to select from three Likert-type response formatted options: low level (coded 1 : the skill is hardly ever used), medium level (coded 2: the skill is 
used sometimes), and high level (coded 3: the skill is used almost always). Examples of items include: "When I have to make a decision, I make a list of possible alternatives to follow." "Before making a decision, I assess its possible consequences." The maximum score of the test is 30 .

The Problem-Solving Test (PS). This test gathers information about the way individuals solve their problems; whether they analyze the available information, identify the most relevant information, plan the solution by stages, overcome difficulties, and assess the results. Ten item-statements are constructed using the same alternative responses as those for the Decision-Making Test. Examples of items include: "Before solving a problem, 1 try to identify all the relevant information provided." "When I have to solve a problem, I carefully plan the steps to follow so as to achieve my goal." The maximum score is 30 .

The Self-Regulation of Learning Test (SR). This instrument offers information about the three phases of the self-regulation process: planning, monitoring, and evaluating. It is made up of 12 item-statements with the same alternative response options as previously described. Item examples include: "Before starling an activity, I choose the most appropriate strategy to help me carry it out." "After finishing an activity, I reflect about the mistakes I made." The maximum score is 36 .

\section{Design}

The working plan corresponded to a quasi-experimental pretest-posttest design with two groups, experimental and control. The independent variable was exposure to the newly constructed portfolio program and the dependent variables wore scores on measures of (a) general intelligence, (b) cognitive flexibility, and (c) metacognitive strategies.

The study was carried out in three phases: pretest, treatment, and posttest. During the pretest phase, participants from both the experimental and the control groups were assessed to examine the homogeneity of the samples on each of the three criteria variables. The data obtained revealed that there were no statistically significant differences between the experimental and control groups: (a) General Intelligence (Gl), $t(107)=-.09, p>.922$; (b) Cognitive Flexibility (CF), $f(107)=.69, p>.643$; and (c) Metacognitive Strategies (MS), $t(107)=-.74, p>.795$. The nonstandardized tests were administered to the experimental group at the end of each of the three terms of the academic school year.

\section{Procedures}

Description of the Portfolio tasks (Treatment). It was hypothesized that the following cognitive processes would improve as a result of the intervention: (a) comparison, (b) categorization, (c) analysis, (d) synthesis, (e) hypothetical reasoning, (f) decision-making, and (g) problem-solving. Further, it was hypothesized that the following metacognitive processes would improve following the intervention: (a) self-knowledge and (b) selfregulation of learning.

The treatment condition consisted of administration of the Portfolio tasks. When designing the Portfolio program, the following criteria were taken into account:

The Portfolio tasks were selected only after reviewing all three programs, consulting external specialists, studying the task sequence in each program, and assessing their motivation potential.

The internal organization of the Portfolio contents was based on a criterion of progressive difficulty-level, as proposed in the programs, which involved: (a) training in the basic cognitive processes first; (b) followed by training in the more complex cognitive tasks such as decision-making and problem-solving; (c) in each term, practicing a certain phase of self-regulation of learning (planning, monitoring, evaluating); and (d) at first, using an individual work methodology, and gradually introducing activities that required cooperative learning.

The representativeness of the tasks in number, variety, and time required were considered in relation to the processes to be improved. That is, each process wats practiced for an equivalent number of exercises and amount of time but using different content. For example, the comparison process was applied to a 20-page assignment in the Instrumental Enrichment program, equivalent to 20) academic hours. Analysis and synthesis processes were practiced for the same amount of time using a 9-page assignment from the Instrumental Enrichment program, an assignment covering 6 episodes from the novel, Lisa (Lipman, 1976) from the Philosophy for Children Program, and 5 lessons from Project Intelligence. This regimen was to insurc that the intervention would focus on a specific process even though the students would be using various but complimentary materials.

The conjoint planning of the tasks selected from the three programs required that the following aspects be taken into consideration: (a) the specific processes to be practiced and the activities to be carried out, (b) the intervention in the classroom according to the three self-regulation phases, (c) class organization (independent or group work), (d) the students' reflections in order to achieve transference, and (c) the evaluation criteria.

The sequence of activity application is shown in Table 1. The first curriculum to be implemented was from the Instrumental Enrichment Program; the second from the Philosophy for Children Program; and lastly, from Project Intelligence. In addition to the programs, Table 1 also indicates the name of the task and the original page numbers where these activities are to be found. 
Table 1

Portfolio Sources and Activities

\begin{tabular}{|c|c|}
\hline PROGRAM & TASKS \\
\hline \multirow[t]{7}{*}{ Instrumental Enriclument } & Organization of Dols Jnstrument. pages: Cover, E3, 6. 8. and 10 . \\
\hline & Categorizations Instrument, pages: 10, 13. 14, and 20. \\
\hline & Analytic Perception Instrument, pages: 9. 12. 15. and 20. \\
\hline & Illustrations Instrument, pages: $2,7,7,9,17$, and 19. \\
\hline & Instructions lustrument, pages: $11,18,2$ and 31 \\
\hline & Tränsitive Relations, pages: $5.9,15$, and 23. \\
\hline & Representational Stencil Design Instrument, pages: A, 3, 8,9, 12, 18, and 23. \\
\hline \multirow[t]{2}{*}{ Philosophy for Children } & Novel Lisa: Chapter I, epesode 1: Chapter II. cpisode 3; Chapter III, episode 5: Clapter IV episode 9: \\
\hline & Chapter V, episode 11: and Clapter XI, episode 25. \\
\hline \multirow[t]{4}{*}{ Project Intelligence } & PROBLEM-SOLVING \\
\hline & Series IV, Lessons: $59,64,68,71$, and 74 . \\
\hline & DECISION-M $\triangle K I N G$ \\
\hline & Series $V$, Lessons: $76.77,78.79,83$, and 84 \\
\hline
\end{tabular}

\section{Program Implementation}

The intervention was performed by one of the authors, who is well-versed in both the theoretical and enpirical aspects of the three programs that make up Portfolio, having been trained by the program authors. The treatment was carried out during an entire academic year, in five weekly 45 -minule class sessions. Three of these classes corresponded to the optional subject "second foreign language." and the other two were tutorial periods. During this lime, the sludents belonging to the control group carried on with their regular academic curriculum, either studying the optional subject (second forcign langtage), or in tutorial classes with their regular teachers.

In addition, approximately 30 hours were spent in meetings and interviews with teachers and parents, both in groups and individually, at three different times throughout the course of this study. At the beginning of the treatment, parents and teachers were informed of the treatment aims, methodology, and matcrials, and they were encouraged to share a positive attitude towards the program with the students. During the second term, the researcher met the teachers and parents to comment on possibic changes in motivation and attitude detected in the students. After the treatment, when the data had becn processed, the findings were discussed with the teachers and parents. The role played by teachers and parents during the administration of portfolio was always indirect. Therefore, no data were gathered from them.

In the final posttest phase, all the participants were reassessed to detect the effects of the intervention. Once again, standardized tcsts of intelligence, cognitive flexibility, and learning strategies were administered along with nonstandardized measures of decision-making, problemsolving, and self-regulation of learning.
Results

An analysis of covariance was performed to find out whether the administration of the nonstandardized SelfRegulation of Learning Test, carried out in the third term, could have influenced the gains oblained in the scores of the learning Strategies Scales, Subscale IV (Roman \& Gallego, 1994), 'The experimental group's pretest learning Strategies Scales (Subscale IV) score was the independent variable, their posttest score (from the same scale) was the depcndent variable, and their third-term score in the Sclf-Regulation of Learning Test was the covariant. At an alpha criterion of .05 , the results showed that the independent variable had a statistically significant effect on the dependent variable, $F(1,49)=5.68, p<.001$, but the covariant did not, $F(1$, 49) $=1.53 . p>.05$.

The pretest-pasttest means contrast for related samples of the experimental group showed statistically significant gains in GI, $t(49)=8.90, p<.001 ; \mathrm{CF}, t(49)=3.75 . p$ $<.001$; and MS, $t(49)=2.36, p<.02 \mathrm{l}$, as can be seen in Table 2 . It is noteworthy that the standard deviation of the experimental group increased from pretest to posttest in GI ( $S D=18.341021 .34)$, and in CF $(S D=$ $10.251012 .48)$, but not in MS $(S D=14.77$ to 12.99). This same pretest-posttest analysis of the control group's scores revealed no statistically significant changes in any of the variables (sec Table 3). In the postlest means contrast for independent samples (sec Table 4). the results of the experimental group were statistically higher than those of the control group in GI, $f(107)=-2.61, p<.01$; in CF, $r(107)=-3.02, p<.001$; and in MS, $t(107)=$ $-3.07, p<.001$. 
Table 2

Pre-and Posttest Changes Obtained by the Experimenal Group in General Intelligence (GI). Cognitive Flexibility (CF), and Metacognitive Strategies (MS)

\begin{tabular}{|c|c|c|c|c|c|}
\hline \multirow{2}{*}{ Mcasures } & \multicolumn{2}{|c|}{ Pretest } & \multicolumn{3}{|c|}{ Posttest } \\
\hline & $M$ & $S D$ & $M$ & $S D$ & $n$ \\
\hline GI & 96.40 & 18.34 & 113.38 & 21.34 & $8.90^{* * * * 4}$ \\
\hline $\mathrm{CF}$ & 38.08 & 10.25 & 50.33 & 12.48 & $3.75^{* * * k}$ \\
\hline MS & 38.66 & 14.77 & 47.22 & 12.99 & $2.36^{*}$ \\
\hline
\end{tabular}

$* p<.05 . * * * * 0.001$

Table 3

Pre-and Posttest Changes Obtained by the Control Group in General Intelligence (GI), Cognitive Flexibility (CF), and Metacognitive Strategies (MS)

\begin{tabular}{lrrrrr}
\hline \multirow{2}{*}{ Meastires } & \multicolumn{2}{c}{ Pretest } & \multicolumn{3}{c}{ Postlest } \\
\cline { 2 - 6 } & $M$ & $S D$ & $M$ & $S D$ & $n$ \\
\hline GI & 99.02 & 18.17 & 101.76 & 17.82 & 1.54 \\
CF & 36.45 & 14.58 & 38.79 & 13.68 & 0.87 \\
MS & 35.43 & 13.23 & 37.84 & 14.03 & 0.69 \\
\hline
\end{tabular}

Note. None of the pre-postlest comparisons was statistically significant at the level of $p<.05$.

Table 4

Contrast of Posttest Means (expressed as t-Values) of the Experimental and Control Group in General Intelligence (Gl), Cognitive Flexibility (CF), and Metacognitive Strategies (MS))

\begin{tabular}{lrrrrr}
\hline Medsures & \multicolumn{2}{c}{ EG } & \multicolumn{2}{c}{ CG } \\
\cline { 2 - 6 } & \multicolumn{1}{c}{$M$} & $S D$ & \multicolumn{1}{c}{ M } & $S D$ & $n$ \\
\hline GI & 113.38 & 21.34 & 101.76 & 17.82 & $-2.61^{* *}$ \\
CF & 50.33 & 12.48 & 38.79 & 13.68 & $-3.02^{* * * *}$ \\
MS & 47.22 & 12.99 & 37.84 & 14.03 & $-3.07^{* * *}$ \\
\hline
\end{tabular}

Note. $\mathrm{EG}=$ Experimental Group; $\mathrm{CG}=$ Control Group.

$* * p<.01, * * * p<0.001$.

The results of the experimental group in the nonstandardized tests were analyzed by means of the nonparametric Friedman test. Statistically significant gains were revealed in the three variables evaluated: $\mathrm{DM}, \mathrm{X}^{2}(2, N$ $=50)=95.11, p<.001 ; \mathrm{PS}, \chi^{2}(2, N=50)=79.44, p<.001$; and SR, $\chi^{2}(2, N=50)=93.96, p<.001$. Figure 1 shows the same improvement, as a function of the means obtained at the end of each term (DM $=13,16$, and 24, respectively; $\mathrm{PS}=12,18$, and 23, respectively; $\mathrm{SR}=14,19$, and 26 . respectively). These results indicate that, after the intervention, the students made decisions in a more reflexive way, were more efficient in solving problems, and attempted to improve planning, control, and evaluation of their school activities. In general, the information from the scores on the researcherdeveloped instruments shows the same tendencies as those revealed by scores on the standardized tests.

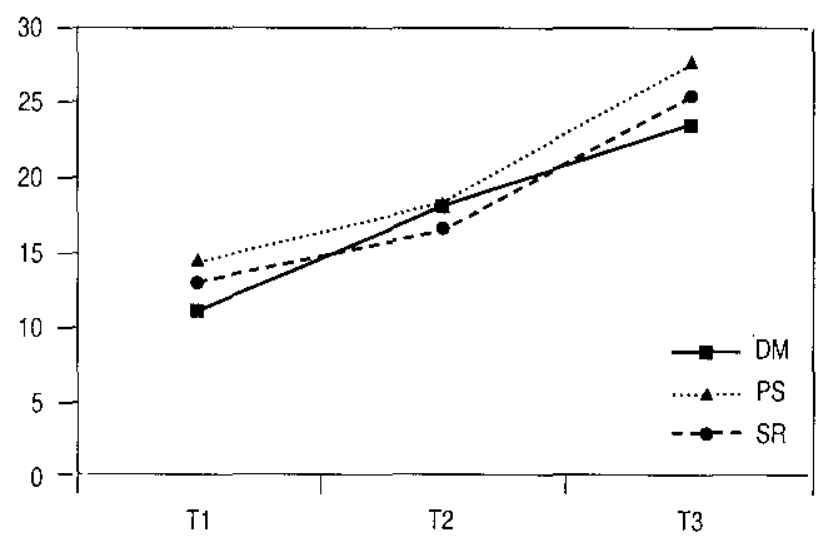

Figure 1. Changes observed in the experimental group in term 1 (T1), term 2 (T2). and term 3 (T3) in Decision-Making (DM). Problem-Solving (PS), and Self-Regulation (SF). 


\section{Discussion}

In general, the results of this study indicate that the Portfolio intervention was effective. That is, the students from the experimental group improved scores that reflected their intellectual capacity, cognitive flexibility, and metacognitive stritegies. More specifically, both the cognitive processes (comparison, classification, analysis, synthesis, generalization, decision-making, and problem-solving) and the metacognitive processes (planning. monitoring, and evaluating) tended to improve, at least in the short term, following participation in the Portfolio lasks. These results conoborate other authors' findings regarding the possibility of enhancing cognitive functioning (De Bono, 1983; Feuerstein et al., 1980; Gardner, 1993; Perkins, 1995; Segal et al., 1985; Sternberg, 1986; Swartz \& Parks, 1994; Whimbey, 1975; Williams et al., 1996) and self-regulation of Jearning skills by means of psychopedagogical programs organized in independent courses (Bockaerts, 1997; Garcia \& Pintrich, 1994; Hacker et al., 1998; Pressley, 1995; Schunk \& Zimmerman, 1994).

To some extent, the enhancement of cognitive and metacognitive capacities for students in the experimental group probably can be related to the presence of certain essential aspects that any psychopedagogical intervention should deliver (self-regulation, mediation, durability, transference, learning strategies, and students' disposition) Even though these factors were not totally controlled in our study, the design and statistical procedures employed provide the basis for drawing tentative conclusions supporting the use of the intervention with secondary students. These aspects have bcen proposed repeatedly by the authors who defend cognitive modifiability (Feuerstein et al., 1980; Paris \& Cross, 1983; Perkins, 1995; Perkins \& Grotzer, 1997; Sternberg, 1986). The groups' age could also have facilitated the task of teaching cognition, because normally, the older the participants are, the greater is their capacity for assimilating thought and self-regulation processes, and they also command a higher, or more technical, level of language which also aids comprehension (Wigfied, Eccles, \& Pintrich, 1996).

The magnitude of the intervention's impact on $G 1$ in the experimental group (see Table 2) was slightly higher than one standard deviation (16.98). This gain is greater than that observed in other studies (Brody, 1992), perhaps because the Culture Fair Intelligence Test, Scale 3, was easy for the students. According to Pinillos (1981), the type of test employed may determine variations in the "g" Factor. Once again, it can be tentatively concluded that academic intelligence measured by psychometric tests increased by means of exposure to these psychopedagogical interventions.

Nevertheless, despitc the gains achieved, the Pottolio intervention did not decrease the individual differences observed between students. The experimental group's postest increase of the standard deviations in $\mathrm{GI}$ and $\mathrm{CF}$ scores may mean that the intervention emphasized the students' inequalities in these variables (see Table 2). As in many other works, our study shows how difficult it is for these intervention programs to "reduce the standard deviation of the distribution by increasing the performance of the less able in proportion to the more able" (Detterntan \& Thompson, 1997, pp. 1086-1087). However, more research on the efficacy of the Porfolio intervention should be carricd out to reassess its reliability and internal consistency, examine whether the gains observed after application are maintained over time, as well as to confirm whether the activities selected from the three programs and their sequence can be recommended to teachers as a course of "teaching how to think."

Another conclusion drawn from this study is that the adolescents who participated in the intervention were more reflexive when making decisions, solved their problems more efficiently, and self-regulated their learning, as shown by the results obtained in the nonstandardized tests. According to the literature. these processes are interdependent. For example, when solving a problem, individuals make decisions about the various strategies they will use and they regulate the available time and resources (Borkowski, Estrada, Milstead, \& Hille, 1989). The parents informed the experimenter that they were quite involved in monitoring their children's participation in the intervention, and this interest may have influenced the students' performance. Therefore, in future research, family environment and related variables should probably be controlled.

It is these authors' opinion that reflexive intelligence can be taught. In other words, the specific cognitive operations that limit intellectual performance cin be corrected, changed. or lavorably modilied by means of appropriate psychological intervention, although, at present, support is inconclusive. Nevertheless, the findings of this study are promising. Educational researchers and teachers should be encouraged to conduct more systematic investigations, working towards the achicvement of this goal.

\section{References}

Blagg, N. (1991). Can we teach intelligcnce? London: Erlbaum. Boekacrts, M. (1997). Self-regulated learning: A new concept embraced by researchers, policy makers, eduators, teachers, and students. Learning and listruction, 7, 161-186.

Borkowski, J.G. Estrada, M.T'., Milstead, M., \& Hale, C.A. (1989). General problen-solving skilts: Relations betwcen metacognition and strategic processing. Leaming Disability Quarterly, 12, 57-70.

Brody. N. (1992). Intelligence. New York: Academic Press

Calderhead. J. (1996). Teachers: Beliefs and knowledge. In D. Berliner \& R. Calfee (Eds.), Handbook of educational pychology (pp. 709-725). New York: Macmillarl. 
Cattell, R.B. (1973). Measuring intelligence with culture fair test (Manual for Scale 2 and 3). Champaign, IL: Instit:ıte for Personality and Ability Testing.

Cattell, R.B., \& Cattell, A.K.S. (1961). Culture Fair Intelligence Test (Scale 2, Forms A \& B). San Antonio, TX: Guidance Testing Assuciates.

Chipman, S., Siegel, J., \& Glaser, R. ( 1985). Thinking and leaming skills: Current research and open questions (Vol, 2). Hilsdale, NJ: Erlbaum.

De Bono, E. (1983). The Cognitive Research Trust (CORT) thinking program. In W. Maxwell (Ed.), Thinking: The expanding frontier (pp. 115-127). Hillsdale, NJ: Erthaum.

Detterman, D.K.. \& Thompson, L.A. (1997), What is so special about special ducation? American Pswchologist, 52, 1082-1090.

Ennis, R.H. (1986). A taxonomy of critical thinking dispositions and abjlities. In J.B. Baron \& R.S. Sternberg (Eds.), Teaching thinking skills: Theory and practice (pp. 9-26). New York: Freeman.

Feuerstein, R.F., Klein, P.S., \& Tinnenbaum, A.J. (1991). Mediated Learning Experience (MLE): Theoretical, psychosocial, and leaming implications. London: Freund.

Feuerstein, R.F., Miller, R., Hoffman, M.B., Rand, Y., Mintzker, Y., \& Jensen, M.R. (1981). Cognitive modifiability in adotescence: Cognitive structure and the effects of intervention. The Journal of Special Education, 15, 269-286.

Feucrstein, R.F, Rand, Y., Hoffman, M., \& Miller, R. (1980). Instrumental Enrichment: An intervention program of cognitive modifiability. Baltimore, MD: University Press.

Frisby, C.L., \& Braden, J.P. (1992). Feuerstein's dynamic assessment approach: A semantic, logical, and empirical critique. Journal of Special Education, 26, 281-301.

García, T., \& Pintrich, P.R. (1994). Regulating motivation and cognition in the classroom: The role of self-schemas and selfregulatory strategies. In D.H. Schunk \& B.J. Zimmerman (Eds.), Self-regulation of learning and performance: lssites and educacional applications (pp. 127-153). Hillsdale, Nf: Erlbaum.

Gaddner, H. (1993). Multiple intelligences: The theory in practice. New York: Basic Books.

Gardner, H. (1999). Intelligence reframed: Multiple intelligences for the 21st century. New York: Basic Books.

Gaskins, Y.. \& Elliot. T. (1991). Implementing cognitive strategy training across the school: The benchnark manual for teachers. Cambridge. MA: Brookline Books.

Greenspan, S., \& Driscoll, J. (1997). J"he role of intelligence in a broad model of personal competence. In D.P. Flanagas, J.L. Genshafe, \& 13.L. Harrison (Eds.), Contemporary intellectual assessment: Thoories. tests, and issues (pp. 131-150). New York: Guilford Press.

Hacker, D.J., Dunlosky, J., \& Graesser, A.C. (1998), Metacognition in educational theory and practice. Mahwah, NJ: Erlbaum.

Halpern, D.F. (1998). Teaching critical thinking for transfer across domains. American Psychologist, 53, 449-455.

Herrnstein. R.J., Nickerson, R.S., Sánchez, M., \& Swets, J.A. (1986). Teaching thinking skills. American Psychologist, 4/. $1279-1289$.
Howe, M.J.A. (1997), $1 Q$ in question: The truth abou intelligence. London: Sage.

lorio, J., Weinstein. M.L.. \& Martin, J.F. (1984). A review of District 24's Philosophy for Children Program. Thinking: The Journal of Philosophy for Children, 5, 28-35.

Klatser, K.J. (1989). Cognitive training program for children. Göttingen, Germany: Hogrefe.

Klauer, K.J. (1998). Inductive reasoning and fluid intelligence: A training approach. In J. Kingma \& W. Tomic (Eds.), Advances in cognition and educational practice (pp. 26 [-289). London: JAI Press.

Lipman, M. (1974). Harry Stottemeier's discovery. Montclair, NJ: Institute for the Advancement of Philosophy for Children, Montclair State College.

Lipman, M. (1976). Lisa. Montclair, NJ: Institute for the Advancement of Philosophy for Children. (Spanish translation: List. Madrid: Ediciones de la Torre, 1988.)

Lipman, M., Sharp, A.M., \& Oscanyan, F. (1980). Philosophy in the classrom. Philadelphia. PA: Temple University Press.

LOGSE (1990). Ley Orgánica de Ordenación General del Sistema Educativo. Madrid: Escuela Española.

Manuel, H.T. (1962). Test of General Ability: Inter-American series (Level 4, Forms A \& B). San Antonio, TX: Guidance Testing Associates.

Nickerson, R.S., Perkins, D.N., \& Smith, E.E. (1985). Teaching thinking. Hillsdate, NJ: Erlbaum.

Nishet, J. (1993). The thinking curriculum. Edirational Psychology, 13, 281-290.

Otis, A.S., \& Lennon, R.T. (1977). Otis-Lennon School Ability Test (Intermediate Level 1, Form R). New York: Harcourt Brace.

Paris, S.G., \& Cross, D.R. (1983). Ordinary learning: Pragmatic connections among children's beliefs, motives, and actions. In J. Bisanz \& R. Kail (Eds.), Learning in children. New York: Springer-Vertag.

Perkins, D.N. (1995). Outsmarting IQ. The emerging science of leamable intelligence. New York: Free Press.

Perkins, D.N.. Goodrich, H.. Tishman, S., \& Mirman-Owen, J. (1994). Thinking connections: Leaming to think and thinking to learm. Menlo Park, CA: Addison-Wesley.

Perkins, D.N., \& Grotzer. T.A. (1997). Teaching intelligence. American Psychologist, 52, 1125-1133.

Perkins. D., Jay, E., \& Tishman. S. (1993). New conceptions of thinking: From ontology to education. Educational Psychologist, $28.67-85$.

Pinillos, J.L. (1981). La mejora cientítica de la inteligencia. Análisis y Modificación de Condicta, 14-15, 115-154.

Pressley, M. (1995). More about the development of self-regulation: Complex, long-term, and thoroughly social. Educational Psychologist, 30, 207-212.

Psychological Corporation. (1978). Metropolitan Achievement Tests (5th ed.). Cleveland, OH: Author.

Rand, Y., Tannenbaum, A.J., \& Feucrstein. R. (1979). Effects of Instrumental Enrichment on the psychoeducational development of low-functioning adolescents. Journal of Edlicational Psychology, 7l, 751-763. 
Resing, W.C.M. (1997). Lcarning potential assessment; The alternative for measuring intelligence? Edtcational and Child Psychology, 14, 68-86.

Resnick, L.B. (1987). Education and leaming to think. Washington, DC: National Academy Press.

Román, J.M., \& Gállego, S. (1994). Escalas de estrategias de aprondizaje. Madrid: TEA.

Sanz de Acedo. M.L. (1989). Efectos del Programa de Enriquecimiento Instrumental en la comprensión de la leclura. en cl rendimicnto escolar y en la habilidad general. Revista Vasca de Psicologa $2,19-31$.

Sanz de Acedo, M.L. (1994). Desarrollo de nuevos estilos de vida en adolescentes: una intervención en rasgos de personalidad y factores cognitivos. Revisfa de Ciencias de la Educación. 157. 29-43.

Scardamalia, M.. \& Bereiter, C. (1985). Fostering the development of self-regulation in chitdren's knowledge processing. In S.F. Chipman, J.W. Segal. \& R. Glaser (Eds.). Thinking and touning skills: Research and open questions (Vol. 2, pp. 563-577). Hillsdale. NJ: Erlbaum.

Schracr, R., \& Stolze, J. (1987). Biology: The study of life. Newton. MA: Allyn \& Bacon.

Schunk, D.H.. \& Zimmerman, B.J. (1994). Self-regulation in education: Retrospect and prospect. In D.H. Schunk \& 13.J. Zimmerman (Eds.), Self-regalation of learning and performance: Issues and educational applications (pp. 305314). Hillsdale, NJ: Eribaum.

Segal, J.W., Chipman, S.F., \& Glaser. R. (1985). Thinking and learning skills: Relating instruction to research (Vol. 1). Hiilsdale, NJ: Erlbaum.

Seisdedos, N. (1994). Test de flexibilidad cognitiva. Madrid: TEA

Shipman, V.C. (1983). Evaluation replication of the Philosophy for Children Program. Thinking: The Joumed of the Philosophy for Children, 5, 45-47.

Simpson, M., Hynd., C., Nist, S., \& Burrel, K. (1997). College academic assistance programs and practices. Educational Psychology Review; 9, 39-87.

Sternberg, R.J. (1985). Beyond IQ: A riarchic of human intelligence. Cambridge, MA: Cambridge University Press.

Sternberg, R.J. (1986). Intelligence applied: Understanding and increasing your intellectual skills. San Diego, CA: Harcourt Bratce.
Stemberg, R.J., \& Wagner, R.K. (1986). Practical infelligence: Nature and origins of competence in the enerday world. Now York: Academic Press,

Swartz. R.J. (1987). Teaching for thinking: A developmental model for the islusion of thinking skills into mainstrean instruction. In J. Baron \& R. Sternberg (Eds.), Teaching thinking skills: Theory and practice (pp. 106-126). New York: Freentan.

Swartz. R.J. (1991). Structured teaching for critical thinking and reasoning in standard subject area instruction. in J.F. Voss, D.N. Perkins, \& J.W. Segal (Eds.), huformal rotsoning and racution (p. 4[5-450). Hillsdale. NJ: Eflbatum.

Swartz, R.j. \& Parks, S. (1994), Infusing the teaching of critical and creative thinking into content instruction. Pacific Grove. CA: Critical Thinking Press \& Software.

Swart7. R.J., \& Perkins, D.N. (1989). Teaching thinking: Lssues and approaches. Pacific Grove. CA: Midwest Publications.

Tishman. S. Perkins, D.N. \& Jay, E, (1995). The thinking chasroem. Boston: MA: Allyn \& Bacon.

Tomic, W., \& Kingma. J. (1996). Three theorjes of cognitive representation and criteriat for evaluating training effects. Edutational Protice and Theor, 18. 15-35.

Tomic, W., Kingma, J., \& Tenvergert. E.M. (1993). Training in mcasurement. Joturial of Educational Research, 86(6), 340348.

Vygotsky, L.S. (1978). Mind in sockty: The developmest of higher pswchological processes. (M. Cole, V. John-Steiner, S. Scribner \& E. Souberman, Eds.). Cambridge, MA: Harvard University Press.

Whimbey, A. (1975). Intligence can be taught. New York: Duton.

Whimbey, A., \& Lochhead, J. (1982). Problem solving and comprehension. Hillsdale, $\mathrm{NJ}$ : Erlbaum.

Wigfical, A. Eccles, J., \& Pintrich, P.R. (1996). Development between the ages of 11 and 25. In D. Berliner \& R. Calfec (Eds.). Handbook of educational psychology (pp. 148-185). New York: Macmillan.

Willams, W., Bilythe, T., White, N., Li, J., Sternberg, R.J., \& Gardncr. H. (1996). Practict intelligence for school handbook. New York: Harper Collins College Publishers.

Received October 28,1999

Revision received June 5, 2000

Accepted October 10, 2000 